UDK: 821.511.141-992

DOI: https://doi.org/10.18485/legado_hispanico.2020.ch10

\author{
Domingo Lilón ${ }^{1}$ \\ Universidad de Pécs \\ Hungría
}

\title{
LAS «MEMORIAS AMERICANAS» DE PÁL ROSTI: «TRAS LAS HUELLAS DE HUMBOLDT»
}

\begin{abstract}
Resumen
El artículo presenta la visión de Pál Rosti (1830-1874), geógrafo, antropólogo y fotógrafo húngaro, sobre su viaje a Cuba, Venezuela y México durante 1856-1859, su opinión sobre diferentes aspectos políticos, económicos y sociales que observara en estos países y que luego redactara en su obra titulada Úti emlékezetek Amerikából (Memorias de un viaje por América), publicada en 1861. Pál Rosti había participado en la guerra de independencia húngara de 1848-1849. Tras la derrota de los húngaros, tuvo que emigrar del país.

Palabras clave: Pál Rosti, memorias, literatura de viaje, América Latina.
\end{abstract}

\section{Introducción}

Como escribiera Miguel de Cervantes a través de su famoso personaje, El Quijote, «el que lee mucho y anda mucho, ve mucho y sabe

\footnotetext{
${ }^{1}$ lilon.domingo@pte.hu

${ }^{2}$ Con estas palabras describe el mismo Rosti su camino hacia los llanos venezolanos («Llanosi út Humboldt után»).
} 
mucho». ${ }^{3}$ Con este aforismo podríamos caracterizar la vida y la obra del geógrafo, etnógrafo y fotógrafo húngaro, Pál Rosti.

Según mi parecer, para difundir el conocimiento relativo a la tierra casi no hay medio más eficaz que el de poder ofrecer claras imágenes mediante fotografías caracterizadoras, fieles, de algunos paisajes de las diversas regiones, sus ciudades, edificaciones, plantas, etc. En consecuencia, considero como una de las tareas principales de mi peregrinación, la elaboración de imágenes de este género, hechas gracias a la fotografía (Correo del Orinoco 2011: 4-5),

escribiría en 1861 en el prólogo de su obra Memorias de un viaje por América. ${ }^{4}$ Para llevar a cabo su empresa, Rosti pasó «alrededor de dos años en Francia e Inglaterra para adquirir los conocimientos y la preparación que necesitaría en mi proyectado viaje y, principalmente, para poder aprender en París el oficio de la fotografía» (Correo del Orinoco 2011: 4-5).

La obra de Pál Rosti, su estudio, podemos clasificarla en cuatro áreas de investigación: a) como fuente histórica debido a que fue testigo presencial, b) como Literatura de viajes, c) como tema recurrente en el latinoamericanismo húngaro, y d) como aporte a la fotografía. ${ }^{5}$

Para los estudiosos venezolanos, la foto que Rosti le hiciera al árbol el Samán de Güere, tiene un significado especial ya que el mismo había sido descrito por Humboldt durante su estancia en Venezuela (1799). Así, en un artículo periodístico titulado «El Samán de Güare: un árbol histórico» se escribe:

\footnotetext{
${ }^{3}$ Como hay tantas ediciones de El Quijote de Cervantes, para simplificar, esta cita la tomo de la página del Centro Virtual Cervantes: [https://cvc.cervantes.es/literatura/clasicos/ quijote/edicion/default.htm] Web 20/09/2019.

${ }^{4}$ Por cuanto la obra completa, Memorias de un viaje por América, no está completamente traducida al castellano, hemos respetado las traducciones parciales que se han hecho. La cita en cuestión se encuentra en el artículo «El samán de Güere. Un árbol lleno de historia», publicado por la revista Correo del Orinoco (No. 32) del 7 de noviembre de 2011, 4-5. La obra que tenemos fue publicada en Budapest en 1992 y en conmemoración del V Centenario del Descubrimiento de América. Rosti dividió su libro en tres grandes capítulos, Cuba, Venezuela y México, enriqueciéndolo con varias de sus fotografías, así como con muchas ilustraciones de las regiones y ciudades visitadas.

${ }^{5}$ Como fuente histórica hay varias publicaciones, especialmente de autores venezolanos en donde su obra ha encontrado un enorme hueco debido a que sólo lo concerniente a Venezuela ha sido traducido al castellano.
} 
Pasaría medio siglo para que el fotógrafo y naturalista húngaro Pal Rosti - afanoso por conocer los estudios botánicos realizados por Humboldtplasmara el imponente samán en su célebre fotografía. Rosti comentó el significado de este singular árbol en el seno del pueblo venezolano, diciendo: «El árbol es muy respetado en toda Venezuela, lo cuidan con esmero y el pueblo tiene veneración por él» (Memorias de Venezuela 2008: 60).

En el siguiente ensayo nos proponemos hacer un enfoque descriptivo de algunos aspectos tales como las clases sociales que distinguió Rosti en los tres países visitados, la geografía, la economía, las costumbres y, naturalmente, la naturaleza, de su obra Memorias de un viaje por América, publicada originalmente en húngaro en 1861. Rosti mismo se había propuesto presentar una imagen de lo visto y experimentado, pero sin la pretensión de un científico. Al respecto escribió:

He tomado la pluma para contribuir, conforme a mi escaso talento, a cubrir el vacío que existe en este género en la literatura nacional. No me gustaría fatigar a mis queridos lectores con el trato científico o con submersión más profunda que tienen cabida en manuales especializados. Máximo me he extendido en este terreno en las notas y en los anexos; tampoco me he adentrado en la descripción de aventuras asombrosas o episodios de esta índole, porque me he cuidado de convertir al viajero relator en un héroe de novela. Mi mayor empeño se ha concentrado en dibujar con colores vivos y mayor naturalidad aquellas impresiones que los paisajes, la vegetación, la gente y sus relaciones ejercieron en mí. Y de esta manera ofrecer a mis compatriotas los conceptos más claros sobre lo experimentado, los informes y las descripciones que corresponden a la realidad (Rosti 1992: s/n).

Considerando el amplio uso de su obra sólo nos queda confirmar y añadir que con creces superó las tareas y finalidades de su viaje.

\section{Biografía de Pál Rosti}

Pál Rosti ${ }^{6}$, geógrafo, etnógrafo, fotógrafo, nació en Pest, el 29 de noviembre de 1830. Procedía de una familia de oficiales y funcionarios. Su padre, Albert Rosty (1779-1847) era un «terrateniente, subprefecto y notario en la comarca de Békés, una persona inteligente y amante de la música y el teatro» (Jancsó 2014: 202). Tenía tres hermanas, dos de ellas

\footnotetext{
${ }^{6}$ El apellido original era Rosty. Sólo Pál cambió la «y» por una «i». En una carta de 1862 escrita por él a János Pompery, editor del Pesti Napló, le corrige alegando con un «Rosti (con «i» y no con «y»)» (Kincses 1992: 5). El por qué de dicha actitud no lo sabemos.
} 
casadas con importantes personajes de la época: «el barón József Eötvös y Ágoston Trefort, demócratas liberales y ambos ministros de cultura, que tuvieron influencia significativa en el desarrollo del joven Rosti» (Jancsó 2014: 202). Este acercamiento a sus cuñados Eötvös y Trefort se acentúa tras la muerte de su padre, Álbert, en 1847. Especialmente Trefort, quien consideraba que los países, pueblos, costumbres, sólo se pueden conocer a través del análisis local y no a través de libros y descripciones.

Pál Rosti «estudió ciencias naturales, especialmente la Botánica, y también música» (Bueno 1977: 75-76). Participó en la Revolución de 1848. Tras la derrota húngara en 1849, su cuñado Ágoston Trefort se lo lleva a Salzburgo. En septiembre de 1849 se matricula en la Facultad de Ciencias Naturales de la Universidad de Munich donde estudió Química. Tras su regreso a Budapest empieza a estudiar Geografía y Etnografía, ingresando en 1853 en la Sociedad Húngara de Geografía. En diciembre de 1854 parte a París donde estudió fotografía ya que comprendía la importancia de ésta en la descripción y el estudio de la Geografía. Rosti «soñaba con emprender un gran viaje, calco de la obra del gran viajero alemán, Alexander von Humboldt, realizado en 1800» (Jancsó 2014: 202).

Antal Vállas, académico, matemático, profesor de Rosti, a quien se le considera el autor de la primera fotografía en Hungría realizada en 1840, influyó mucho también en su vida y su obra, tanto desde las Matemáticas como desde la fotografía. En 1851 Vállas emigró a los EE UU, asentándose un tiempo en New Orleans. No accidentalmente Rosti pasaría un tiempo en esta ciudad, recibiendo, quizás, consejos de su antiguo profesor. Vállas había vivido también dos años en Nicaragua como propietario de una plantación de café. Sin duda alguna, el viejo maestro le hubo de contar cosas interesantes de este país y región.

El 4 de agosto de 1856 parte desde Havre de Grace (Francia) rumbo a los EE UU, país donde vivió siete meses. De los EE UU viajó a Cuba, Venezuela y México, para regresar a Hungría el 26 de febrero de 1859. En 1861 publica su obra Memorias de un viaje por América, e ingresa en la Academia Húngara de Ciencias. Muere en Dunapentele, el 7 de diciembre de 1874.

\section{Cuba, Venezuela y México: Memorias de un viaje por América}

Pál Rosti tenía 26 años cuando partió para América, estando allí un año y cuatro meses. Sin embargo, dedicó seis años de su vida a preparar su gran viaje. Durante dos años pudo reunir, recopilar y organizar todo el material que necesitaría en su hazaña tras las huellas de Humboldt. 
Por sus viajes y estudios sabemos que hablaba inglés, alemán y francés. No tenemos constancia sobre sus conocimientos de español, pero por las explicaciones y notas en su libro Úti emlékezetek Amerikából (Memorias de un viaje por América) podemos deducir que sí lo dominaba hasta cierto nivel.

Pál Rosti fue un observador meticuloso, observador atento de todo lo que sucedía a su alrededor. De esa forma pudo describir paisajes, flora y fauna, composición social y étnica de las poblaciones, producción económica y situación política de todos aquellos lugares visitados. Naturalmente, conforme a su tarea propuesta, no sólo los describió con palabras en su libro Memorias de un viaje por América, sino también los plasmó en sus fotografías.

La Cuba a la que Rosti arribaría en 1857 era la Cuba esclavista que había conocido Alexander von Humboldt y sobre la cual había escrito una obra titulada Ensayo político sobre la isla de Cuba y en la que describe la esclavitud como «el mayor de todos los males que han afligido a la humanidad» (Humboldt 2005: 220). Un poco más de una década después, en 1868, se iniciaría en Cuba la llamada «Guerra de los diez años» (18681878) o "Guerra grande», primera guerra de independencia contra España. Unos meses más tarde, Rosti llegaría a la Venezuela gobernada por el general José Tadeo Monagas, quien sería derrocado por una revolución en 1858. Su hermano, José Gregorio Monagas, presidente de la República entre 1851 y 1855, había abolido la esclavitud en 1854. Por su parte, el México visitado por Rosti era el México de la Constitución liberal de febrero de 1857 y que sería promulgada en marzo del mismo año. México era escenario de la lucha entre liberales y conservadores. Los liberales, dirigidos por Benito Juárez, habían llegado a la presidencia y en 1861 suspenderían el pago de la deuda externa. Como resultado de ésto, Francia, Reino Unido y España decidieron intervenir. Con el apoyo de Francia, que había ocupado la capital, en 1863 se estableció el imperio en México con Maximiliano de Habsburgo como emperador, imperio que duró hasta 1867 cuando fue derrotado por las fuerzas liberales.

\section{Cuba}

Sobre Cuba hizo una descripción general del país, escribió sus experiencias de un domingo en la ciudad de La Habana, sobre el clima, sobre las plantaciones de cañas y la producción de azúcar, sobre la esclavitud, sobre la composición étnica de la población, sobre los colonos chinos y las plantaciones de tabaco y la producción de cigarro. Su estancia en Cuba fue muy fructífera en experiencias. 
Salvador Bueno (1977: 76) y Katalin Jancsó (2014: 205) destacan la descripción que hace Rosti sobre la volanta, coche tirado por caballos que era muy popular en el Caribe y que según él, funcionaba «a pesar de romper todas las leyes del equilibrio».

Tras una descripción técnica de la volanta, Rosti considera que dicho artilugio es «una verdadera tortura al animal, principalmente si vemos a un famélico caballo que apenas puede mantenerse de pie y que sin embargo lleva por las estrechas calles a los pesados volantero y calesero» (Rosti 1992: 4). ${ }^{7}$ Según Rosti, todo el mundo utilizaba la volanta, independientemente del color de la piel, el rango, la pertenencia racial: el tendero, el comerciante, el político, la cocinera, etc. Es decir, todos los estratos sociales de la sociedad habanera de la época.

Naturalmente, la volanta servía no sólo como medio de transporte rápido y eficiente, sino también para mitigar ese calor tropical que él mismo experimentara. Según Rosti (1992: 4), «durante el día en La Habana, es decir entre las 9-5 horas ${ }^{8}$ sólo sale de su habitación aquel que tiene asuntos que atender y de poder hacerlo, entonces en la mencionada volanta».

En su Egy vasárnap Habanában (Un domingo en La Habana) hace una excelente descripción de su experiencia habanera. Según Rosti (1992: 6), «el domingo es el día más interesante para los extranjeros», porque ese día se enriquece con cuadros originales. Por esto hay que entender la forma en que se visten ese día los habaneros de diferentes orígenes socioeconómicos, así como también las diferentes actividades «domingueras».

La vida social (y religiosa) de un domingo cualquiera en La Habana, según Rosti, empieza temprano, entre las 6:00-9:00 a.m., en la Iglesia. A ella asisten todos, los señores, los mulatos, los esclavos, todos bien vestidos, especialmente las mujeres. Claro, con sus respectivas diferencias: las más ricas mucho mejor vestidas que las esclavas. Por lo general, las primeras llegan en las volantas, las últimas a pie.

Las iglesias no tenían butacas (como en Hungría) o sillas (como en Francia), algo que le llamó la atención a Rosti. Por ello, al templo entraba primero un joven negro, extendía una pequeña alfombra sobre la cual se arrodillaban luego, o se sentaban durante la misa, las señoras (blancas) junto con sus hijos. Las mujeres siempre ocupaban el centro del templo, mientras que los hombres se mantenían de pie o arrodillados, pero

\footnotetext{
${ }^{7}$ Las traducciones son del autor de este ensayo.

8 9:00 a.m.-5:00 p.m. D.L.
} 
siempre a los lados. Para Rosti, el ver sentadas o arrodilladas a las señoras blancas y ricas, con su distinguida vestimenta, a las mulatas, con su ropa veraniega y siempre descotada y a las negras esclavas, vestidas con ropa de las señoras, era un auténtico y original cuadro de la sociedad.

La misa iba acompañada de música clásica interpretada por algún grupo musical de negros, que según Rosti, «para un oído europeo es tarea difícil escuchar hasta el final». Especialmente si se interpretaba a Haydn o a Mozart (Rosti 1992: 7).

Otro asunto que le llamó la atención a nuestro viajero fue que tras finalizar la misa, la mayoría de los jóvenes se colocaban a la salida de la iglesia para así intercambiar una que otra mirada o, de tener más suerte como el mismo Rosti, «poder ver unas bellas piernas al subir a la volanta» (Rosti 1992: 7).

Tras la misa, el siguiente acontecimiento social, al menos para los hombres, era ir al Valle de Gallos, en La Habana, a las 11:00 a.m para presenciar o participar en las peleas de gallos. En este evento matiza también que no se trata sólo de una pasión popular, de la gente llana del pueblo, sino también de los ricos. Describe Rosti detalladamente estas peleas de gallos en donde los animales pelean hasta el final. Según Rosti, esta pasión (de gallos y peleas) es característica de los pueblos hispanos.

A partir de las 4:00 p.m. la siguiente actividad social de los hombres era la plaza de toros. Durante el verano se realizaban actividades cada domingo; en invierno, cada segundo domingo. Las corridas de toros, según Rosti, eran más terribles que las peleas de gallos. Para él no era más que una tortura hacia los animales. En esta actividad, matiza, no participaban las mujeres.

A partir de las 5:00 p.m. la mayor actividad era dirigirse al Paseo de Tacón que conllevaba a la Calzada de la Reina y al Fuerte Príncipe. Allí asistían todos de la mejor forma vestidos, llegándose a reunir cientos de volantas. Para Rosti, el hecho de que en La Habana hubiesen relativamente más volantas que en las grandes ciudades de Europa se debía a que en La Habana había muchos ricos. Además, para las mujeres de La Habana, la volanta era una conditio sine qua non: la mujer que se considerara a sí misma parte de la alta sociedad nunca va a pie, nunca baja de la volanta, incluso si se dirige a la tienda «es el comerciante infeliz el que debe llevar su mercancía, a veces todo su almacén, a la volanta. Puedo decir sin exagerar que hay mujeres que durante todo el año no habían dado ni diez pasos fuera de su casa» (Rosti 1992: 11; Bueno 1977: 76).

Según Rosti, muy pocos hablaban lenguas extranjeras. Igual impresión negativa tuvo sobre la educación y las artes. 
Durante los dos meses de estancia en Cuba, Rosti pudo llevar a cabo varias actividades como la de visitar algunos ingenios azucareros («Isabel», «La Unión»), viendo cómo se desarrollaba la fabricación de azúcar, proceso que luego describiría en sus escritos. Visitó plantaciones de tabaco y café, pudiendo constatar allí el trabajo de los esclavos, sacando sus propias conclusiones respecto a la mano de obra esclava en las diferentes ramas de la producción agrícola, así como con respecto a la situación de los negros en los EE UU. Un dato interesante lo ofrece respecto a los trabajadores chinos, mejor conocidos como culíes.

Rosti dedicó algunas páginas de su libro Memorias de un viaje por América para escribir sus experiencias sobre la esclavitud en Cuba. Según él, los negros eran inferiores a los blancos ya que «Dios creó a los negros más fuertes físicamente, pero más débiles intelectualmente que los blancos» (Rosti 1992: 20). Pero matiza que esta diferencia se debe, principalmente, a la forma en que son educados, socializados: sin escuelas, educación religiosa, etc., los negros no tienen otro camino más que el trabajo físico en las plantaciones, las fábricas o el servicio doméstico.

Según él, los esclavos estaban satisfechos de su suerte y su situación; «no vi a ninguno triste», escribiría en su obra. Para Rosti, el eterno buen estado de ánimo y de humor eran característicos de ellos (Rosti 1992: 21). Habiendo estado en los EE UU, donde también fue testigo del sistema esclavista, Rosti tenía fundamento para hacer una comparación con la esclavitud que existía en Cuba. Según él, las leyes esclavistas cubanas eran más humanas que las de otro Estado esclavista. Por ejemplo, en Louisiana (EE UU), los esclavos no podían poseer ningún bien sea recibido, ganado o robado, porque todo pertenecía al amo. En Cuba, mientras, sí era posible, pudiendo ejercer el esclavo su derecho de propiedad como el de cualquier hombre libre. Según él, en La Habana se trata tan bien a los esclavos que apenas puede percibirse que se trata de un Estado esclavista, "principalmente si se lee una obra como La cabaña del Oncle Tom (sic)» (Rosti 1992: 23). Esa misma impresión de la «felicidad» de los esclavos cubanos era la que le harían saber a Rosti los esclavistas cubanos. Al menos en las conversaciones que él sostuvo con varios de ellos, éstos se lo expresaron más de una vez.

Rosti consideraba que la situación de los negros esclavos cubanos era similar a la de los trabajadores pobres de Europa ya que ambos se enfrentaban a los mismos problemas materiales como lo eran el mantenimiento de la familia, la salud, etc.

El trabajo en los ingenios azucareros era el más pesado para los esclavos cubanos, donde se trabajaba en jornadas de 6 horas; un grupo 
sustituía a otro. El trabajo allí lo controlaba un «inspector», esclavo él también, quien con gritos y su látigo mantenía el orden. Sin embargo, durante su estancia en Cuba Rosti no vio nunca alguna situación en que el uso del látigo fuera necesario. Mientras trabajaban, los esclavos cantaban «si por canto entendemos algunos sonidos y gritos» (Rosti 1992: 20).

Para Rosti y cualquier europeo, el clima era lo peor del trabajo. Sin embargo, según sus palabras, para los negros el calor no significaba dificultad alguna. Al contrario, sufrían si bajaba la temperatura (para felicidad de los europeos). Rosti comparaba a los negros con los caimanes del Orinoco, capaces ambos de pasar horas bajo los rayos del sol. Por lo general, la época de la cosecha (5 meses) era la más fatigosa para aquellos esclavos que trabajaban en las plantaciones de caña de azúcar y de plátanos, ya que estos cultivos no requerían muchas labores o atenciones. Los esclavos que trabajaban en los ingenios podían tener gallinas y cerdos, incluso un poco de tierra para cultivar. Sin embargo, «en esta bendecida región, donde sólo se necesita sembrar y cosechar, a menudo no se hace por pura pereza» (Rosti 1992: 21).

Los esclavos que trabajaban en las ciudades, por ejemplo, en las fábricas de cigarro o en el servicio doméstico, tenían mejor suerte que los que trabajaban en los ingenios, siendo el mayor castigo para los primeros ser enviados a trabajar a las plantaciones en caso de haber cometido algún robo o infidelidad al amo.

Un esclavo fuerte costaba unos 500 dólares, aumentando su precio a 1,500-2,000 dólares en caso de éste haber aprendido algún oficio, por ejemplo, para ser cochero, cocinero, etc.

Los esclavos cubanos podían obtener su libertad, entre otras, mediante la gracia, el favor del amo como recompensa a los servicios y fidelidad prestados durante años. Sin embargo, en muchas ocasiones rechazaban esta libertad. En su libro, Rosti hace referencia a un caso del cual él fue testigo. Según su relato, «don J. Jorrín», un rico terrateniente cubano llevó consigo a dos esclavos suyos durante su larga estancia en Europa; uno como mayordomo, otra como ama de casa. Tras su regreso a Cuba organizó un almuerzo al cual invitó a sus amigos. Al final del almuerzo y tras explicar que durante su estancia en Europa sus esclavos disfrutaron de la «libertad», por cuanto en Europa no existía ya la esclavitud, decidió otorgarles la libertad. Para sorpresa de todos, también para Rosti, ambos esclavos rechazaron la regalada libertad, alegando que no la querían, que se sentían muy bien en casa del amo. Para Rosti, la explicación a esta actitud radicaba en que como hombres libres, los esclavos no representaban ya una carga para los amos, es decir, ellos 
tenían que obtener la forma y los medios para alimentarse, vestirse, vivir. Por eso preferían seguir siendo esclavos. Según Rosti, muchos ex-esclavos terminaban en la cárcel o regresaban a casa de sus amos.

Por último, Rosti se sorprendía de que con tantos esclavos las casas estuvieran «sucias y desordenadas»: «Es un hecho que si en La Habana se necesitan 10 esclavas para mantener el orden en una casa, en Europa se necesitarían sólo 2» (Rosti 1992: 23).

\section{Venezuela}

En 1857, y desde La Habana, parte hacia la isla de St. Thomas y de allí al puerto de La Guaira, Venezuela. Estando allí se hospedó en la hacienda llamada El Palmar, ubicada en Aragua y cuyo propietario era Francisco (Franz) Vollmer, terrateniente venezolano de origen alemán.

La descripción que hace de la hacienda, la producción de azúcar (papelón) y el cultivo del café, el aguardiente, la música y la gente que conoció nos dan una imagen de una parte de la Venezuela de la época. Sobre la hacienda escribe:

Cerca de la población de San Mateo, hacia el centro del valle de Aragua, está situada la hacienda El Palmar, posesión del seńor Francisco Vollmer [sic.], para quien tenía una carta de recomendación, proporcionada por un común amigo de Caracas.

Arribé, pues, a El Palmar, donde fui objeto de un recibimiento tan amistoso, que realmente sólo lo puedo comparar con la hospitalidad húngara. Aunque tenía la intención de permanecer allí sólo algunas horas, o -como máximo- un día, cediendo a mi amable anfitrión -que me retenía constantemente- estuve con él todo un mes. Tuve así la oportunidad de conocer bastante de cerca el valle de Aragua, su flora, el carácter y las costumbres de sus gentes y también algo sobre el manejo de las plantaciones de café (http://fundavollmer.com/?page_id=174).

Rosti, gran observador, describe la casa de la siguiente manera:

La casa de habitación del seńor Vollmer está entre los cafetales y los cańamelares, frente al trapiche y al alambique. Es una casita sencilla, cuadrada, de dos pisos, rodeada de corredores de madera, de techo bajo y con aleros, que dan sombra al corredor. La casa es de los viejos tiempos; gruesas vigas, hechas de resistente madera de cedro, sostienen el techo y las paredes principales. El mobiliario es también sencillo, está lejos de ser brillante o de estar de moda, no obstante es agradable (http:// fundavollmer.com/?page_id=174\&page=4). 
Sobre el valle de Aragua, donde pasó cierto tiempo, Rosti escribe:

En el valle de Aragua el café constituye la principal riqueza de la región, así como el azúcar en la isla de Cuba. La plantación de café generalmente dura mucho, existen en Venezuela algunas de sesenta o setenta años; la de El Palmar tiene aproximadamente treinta. En ella se producen anualmente -en números redondos- 2.000 quintales de café. El señor Vollmer tiene también, en El Palmar, una plantación de caña de azúcar. El cultivo de la caña y la preparación del azúcar se diferencian en parte de los procedimientos usuales en la isla de Cuba (http://fundavollmer.com/?page_id=174),

En el valle de Aragua no hay animales salvajes ni carnívoros, a lo más existen serpientes venenosas, aunque yo -pese a mi búsqueda entre las cañas y las hierbas y en las espesuras- no pude ver ninguna. En el porche de la casa hay una boa constrictor disecada del grueso de un muslo de hombre y de un tercio del brazo de largo, que mataron en las tierras del señor Vollmer. Don Federico me mostró cinco o seis serpientes Klaris en alcohol, una de las cuales había sido hallada, entre la caña, durante mi estada en la hacienda. Es, pues, indudable que hay serpientes en el valle de Aragua (http://fundavollmer.com/?page_id=174\&page=4).

Rosti, que había visitado en Cuba algunos ingenios, aprovechó su estancia en El Palmar para ver la elaboración del papelón y el azúcar morena no refinada, sobre los cuales escribió:

En El Palmar, como en todo el Valle de Aragua, no fabrican azúcar de la caña -como en la Isla de Cuba-, sino papelón y aguardiente. El papelón no es - en esencia - otra cosa que el azúcar morena o granulada, no refinada, o sea, el guarapo de caña espesado, es decir, en estado sólido; su elaboración es mucho más sencilla que la del azúcar. El Trapiche, que muele la caña, es -por lo general- impulsado con agua en el valle de Aragua y está construido por tres cilindros de hierro, dan vueltas en sentidos contrarios. El zumo extraído, o sea el guarapo, lo cocinan sucesivamente en tres calderas, hasta que se transforma en un espeso melado, entonces lo vierten en vasijas cónicas de barro y lo enfrían. Al evaporarse la parte acuosa queda un cono sólido, color café oscuro, de una libra y media, que sacan del recipiente y envuelven en hojas secas de plátanos. Este es el papelón. En Venezuela -exceptuando las casas nobles- emplean en general al papelón en lugar del azúcar. Este artículo juega un gran papel en la economía doméstica de los criollos, tan aficionados al dulce, y lo utilizan en la preparación de confituras y dulces, de los cuales hay algunos cuyo sabor no es precisamente malo. En muchos lugares -sobre todo en los 
Llanos- vi que usaban el papelón a modo de pan, verbigracia, lo comían con un trozo de queso en el desayuno. Indudablemente, dado su contenido de melaza, tiene gran valor nutritivo. Su sabor -cuando nos hemos acostumbrado a él- no es desagradable. Disuelto en agua caliente (el nombre de esto es también guarapo), con una o dos gotas de zumo de limón y con ron es una bebida agradable y sana (http://fundavollmer. com/?page_id=174\&page $=2$ ).

Sobre el aguardiente escribe:

Junto al trapiche está el alambique, o destilería de aguardiente. La destilación del aguardiente es bastante sencilla. Hierven el guarapo en grandes cubos abiertos y luego lo destilan en sencillos aparatos. La demanda del aguardiente es tan grande que el señor Vollmer no tiene un barril en la bodega, es más, no tiene bodega; en cuanto se elabora, se vende. Preparan trescientas cargas mensuales. Cuando estuve allá el precio de una carga era de doce dólares, pero su precio regular es de sólo seis a ocho dólares (http://fundavollmer.com/?page_id=174\&page=3).

Gran aficionado a la música, Rosti pudo deleitarse con interpretaciones a cargo del mismo anfitrión, Federico Vollmer Ribas, ejemplo de la cultura musical característica de las élites y de la cual el mismo Rosti mucho recibió en la casa paterna:

A la tardecita cabalgábamos - comíamos de seis a siete-. La noche estaba consagrada a la conversación y a la música. Debido al excelente intérprete de piano que era don Federico, pude deleitarme, también en la zona tórrida, con las sonatas de Beethoven y Mozart y con canciones de Mendelssohn y Schubert. Hacia las once nos acostábamos, quedando las puertas y ventanas totalmente abiertas (http://fundavollmer.com/?page_ id=174\&page $=5$ ).

Federico Vollmer ofrecería un "haromocho", es decir, una fiesta en honor a Rosti. De esta forma, el gran observador viajero húngaro pudo familiarizarse con la música, los bailes e instrumentos musicales de la región, así como con parte de sus vecinos y sus costumbres:

Don Federico y algunos de sus amigos organizaron en Cagua, localidad cercana a El Palmar y situada entre cafetales, un "haramocho" o fiesta en mi honor. La concurrencia estaba formada por las capas superiores de la gente del pueblo. Todas las mujeres y la mayoría de los hombres eran mestizos. Algunas velas de sebo iluminaban con excesiva modestia la 
pequeña habitación, de la pequeña casa campesina. En un rincón estaba la orquesta, es decir, un arpa desafinada, que acompañaba un negro con su canto, o mejor con gritos recitados, mientras otro hacía sonar las maracas. La maraca se hace con una totuma, aproximadamente del tamaño de una bala de cañón de seis libras, en la cual se ponen granos de maíz; a ésta se le añade un mango. Saben hacer sonar este instrumento, único en su género, con singular habilidad y según diferentes ritmos. Acompañan el arpa y las maracas con cantos, que gritan o recitan monótonamente y que no posee interés musical ni poético; su tema es casi siempre el amor y no pocas veces es atrevido.

Es costumbre cuando entra un señor noble, improvisar versos en su nombre y los gritan hasta que reciben dinero. Existen diversos bailes; hay una especie de vals muy lento; asimismo, hay otro que se parece a nuestra csárdás, sólo que es mucho más lento. Intervienen en él cuatro parejas, al terminar el verso los cuatro bailarines se retiran y las cuatro muchachas escogen nuevas parejas, tirándoles sus pañuelos, si los tienen. Al terminar nuevamente el verso, son las bailarinas las que se alejan y los hombres son los que escogen pareja, y así sucesivamente. Una de las bellezas morenas de brillantes ojos me honró con su escogencia. Mis amigos creyeron que por ser forastero iba a quedar mal en el desconocido baile, pero, estando iniciado en los secretos de la csárdás, salí mal que bien del aprieto, ante la admiración de los presentes. Al terminar cada pieza las mujeres se sientan en fila, en estrechos bancos colocados contra las paredes, y no dicen una palabra en toda la noche. Los hombres, que conversan o fuman formando grupos, no se ocupan de ellas en lo más mínimo. ¡Cuán diferente es esto de nuestras alegres y bulliciosas fiestas! (http://fundavollmer.com/?page_ id=174\&page=6).

Los cinco meses de estancia de Rosti en Venezuela fueron de una experiencia inolvidable. Además de conocer lugares como La Guaira, Caracas, San Juan de los Morros, Angostura, Rosti tuvo también la posibilidad de examinar la flora y la fauna, la composición social de los habitantes de ciudades y del interior como los llanos, el Orinoco, etc.

Pero quizás lo más simbólico, lo más ilustrativo de su estancia en Venezuela es aquella fotografía que tomara al Samán de Güere, árbol al que Humboldt había hecho referencia durante su viaje a América y que Rosti, con su fotografía, inmortalizaría. Mucho más emoción le produce cuando el 1 de noviembre de 1858, Rosti le entrega al maestro una copia de esta fotografía.

En julio de 1857, Rosti arriba a México. 


\section{México}

La estancia en México le aportó también a Pál Rosti una experiencia extraordinaria y de primera fuente. La Geografía, la flora y la fauna figuran entre los primeros temas que llaman su atención, especialmente lo relacionado con el cultivo del maíz, del pulque.

Igual de importantes son las visitas que hace a Veracruz, Orizaba, Ciudad de México, como también a Popocatepelt, Palenque.

La población, los indígenas, la composición étnica y social del país, el papel de la Iglesia fueron temas de interés del viajero húngaro, así como también las manifestaciones culturales, especialmente las festividades religiosas (Semana Santa, Día de los Muertos, Nochebuena, etc.). De la amplia y enriquecedora experiencia mexicana de Rosti queremos destacar las relativas a las festividades, las cuales él mismo enmarcó en un apartado titulado Mexico ünnepel (México festeja).

Dentro de las múltiples festividades mexicanas, Rosti prestó gran atención, entre otras a cuatro de ellas: a) la Fiesta Nacional, b) el Día de los Muertos, c) la Navidad y d) la Semana Santa.

La Fiesta Nacional de México, el 16 de septiembre, la presenta haciendo una descripción de la ornamentación de la festividad, especialmente en los teatros Iturbide y Nacional, lugar desde donde los oradores se dirigirían al pueblo, matizando el poco interés y atención de los presentes.

Rosti resalta la importancia de El Día de los Muertos en México. Lo presenta mediante una descripción de una morada indígena en donde predomina el orden, la limpieza, la ornamentación con flores, mientras las mujeres preparan tortillas y demás platos para ofrendar a los parientes muertos. Entre las comidas figuran el huajalote (pavo), el chile, los tamales, así como el pulque y el mescal.

Otra fiesta religiosa importante en México es la Navidad. Sin embargo, para él, acostumbrado a la tradición germana del árbol de Navidad, echa en falta esta tradición en México como resultado, según su opinión, de la ausencia de dicha tradición en España, Italia o Francia. Si allí no la hay, entonces en México tampoco. La Navidad, tal como la describe Rosti, se celebra con dulces, pasteles, establos y belenes, entre otros. Destaca la enorme cantidad de iglesias que hay en el país desde donde se llevan a cabo fuegos artificiales. Los ricos, entonces, regalan ropa y dinero a los pobres.

Rosti se hace eco también de la Semana Santa en México. Destaca que ya a partir del Domingo de Ramos se inician las festividades religiosas, 
destacando la procesión que empieza el Jueves Santo y que durante el Viernes Santo se mantiene en silencio.

Por último, agrega la festividad de Nuestra Seńora de la Virgen de Guadalupe, el 12 de diciembre, como otra de las grandes festividades religiosas mexicanas.

En noviembre de 1858, y de regreso a Hungría, Rosti viaja a Berlín para visitar a Humboldt, guía suyo en su gran empresa americana. Rosti había leído las obras de Humboldt, continuando parte de la ruta del sabio alemán. Además había recibido de Humboldt cartas de recomendación que le sirvieron de mucho en su viaje a América. En Berlín le regaló a Humboldt un primer ejemplar de su libro de fotografías que había hecho en París. Cuando Humboldt vio la foto del Samán de Güere, aquel árbol sobre el cual había escrito lo siguiente medio siglo antes,

Al salir del pueblo de Turmero, a una legua de distancia, se descubre un objeto que se presenta en el horizonte como un terromontero redondeado, como un túmulo cubierto de vegetación. No es una colina ni un grupo de árboles muy juntos, sino un solo árbol, el famoso Samán de Güere, conocido en toda la provincia por la enorme extensión de sus ramas, que forman una copa hemisférica de 576 pies [180,8 metros] de circunferencia... Los habitantes de estos valles, y sobre todo los indios, tienen veneración por el Samán de Güere, al que parecen haber hallado los primeros conquistadores poco más o menos en el mismo estado en que hoy lo vemos. Desde que se le viene observando atentamente no se le ha visto mudar de grosor ni de forma (Correo del Orinoco 2011: 4-5).

dijo: «Este hermoso árbol está lo mismo ahora que hace sesenta años: ninguna de sus ramas se ha doblado; está exactamente tal y como lo contemplé con Bonpland cuando éramos jóvenes, fuertes, llenos de vida [...]» (Jancsó 2014: 203).

Antes de regresar definitivamente a Hungría, el 4 de noviembre de 1858, Rosti había hecho cuatro libros de las fotografías que había tomado en Cuba, Venezuela y México. Un ejemplar regaló a Humboldt en Berlín, el cual hoy día se encuentra en el Deutsches Museun. El ejemplar que regaló a su hermana Ágnes Rosty y a su marido, el barón József Eötvös, se encuentra en el Instituto de Geofísica Lóránd Eötvös, el ejemplar regalado a su otra hermana. Ilona Rosty y a su esposo, Ágoston Trefort se encuentra en el Museo de Fotografía en Hungría. Un cuarto libro de fotos se encuentra en el Museo Nacional de Budapest.

$\mathrm{Ni}$ antes de su viaje a América, ni después de su retorno a Hungría conocemos fotos de Pál Rosti lo que ha llevado a varias conjeturas tales 
como que los conocimientos adquiridos en París los dedicó sólo para este viaje suyo a América, o que de haberlas, las fotos, éstas se han perdido.

En 1861, y tras dos años de su regreso definitivo a Hungría, publica su Memorias de un viaje por América con la colaboración del litógrafo Gusztáv Kletle, quien le ayudó a pintar las fotos que había tomado para la publicación de su obra.

\section{Conclusión}

La vida y la obra de Pál Rosti ocupan un lugar preferencial en las relaciones Hungría-América Latina. La obra de Rosti la podemos analizar desde diferentes ópticas, desde diferentes fuentes, y ese es su gran poder de atracción. Que nuevas y nuevas generaciones sigan escribiendo, ocuparse de la obra de Rosti es la mejor explicación.

Con sus escritos, sus fotografías, Rosti desempeñó un gran papel en la divulgación de América Latina en la sociedad húngara de la época y posterior a él. Pero no sólo en Hungría y los húngaros, sino también entre los mismos latinoamericanos, tal cual el caso de Venezuela donde su obra es motivo constante de estudio, de publicaciones.

Tras su regreso a Hungría se dedicó a las ciencias, fue miembro de la Academia Húngara de Ciencias. Pero se dedicó también a otras actividades favoritas suyas, como el deporte, la música. Escribió también varias crónicas sobre su viaje a los EE UU y que fueron publicadas en Hazánk $s$ a Külföld. El final de su vida lo pasó en Dunapentele, donde murió en 1874.

No teniendo familia, se complacía en la belleza y la naturaleza. Aquí olvidó sus dolores y endulzó su vida en compañía de sus amigos, sobre todo de sus conocidos pintores, músicos y parientes. Este año ha contemplado por última vez cómo sus rosas han florecido y se han marchitado, y sus pétalos ahora caerán sobre su tumba... reza la nota necrológica recogida por Vasárnapi Újság del 20 de diciembre de 1874 (Jancsó 2014: 207).

\section{REFERENCIAS BIBLIOGRÁFICAS}

Bueno 1977: Salvador Bueno. Cinco siglos de relaciones entre Hungría y América Latina. Budapest: Editorial Corvina.

Cervantes [S.A.]: Miguel de Cervantes, El Quijote.

[https://cvc.cervantes.es/literatura/clasicos/quijote/edicion/ default.htm] Web. 20/09/2019. 
Correo del Orinoco (No. 32) del 7 de noviembre de 2011, [http://fundavollmer.com] Web. 20/09/2019.

Humboldt 2005: Alexander von Humboldt. Ensayo político sobre la isla de Cuba. Caracas: Biblioteca Ayacucho.

Jancsó 2013: Katalin Jancsó. «Húngaros en los trópicos. Rosti Pál y otros viajeros en el Caribe y en América Central en la segunda parte del siglo XIX». Acta Hispanica. Szeged: Departamento de Estudios Hispánicos, 73-83.

Jancsó 2014: Katalin Jancsó. «El viajero Pál Rosti: siguiendo las huellas de Humboldt en los trópicos». Ibero-Americana Pragensia Supplementum 35: 199-207.

Kincses 1992: Károly Kincses. Rosti Pál 1830-1874. Kincses Károly tanulmánya az Úti emlékezetek Amerikából hasonmás kiadásához (Pál Rosti 1830-1874. Ensayo de Károly Kincses sobre la edición de Memorias de un viaje por América). Budapest: Magyar Fotográfiai Múzeum.

Memorias de Venezuela, Julio-Agosto 2008, No. 4: 60.

Rosti 1992: Pál Rosti. Úti emlékezetek Amerikából (Memorias de un viaje por América). Pest. Kiadja Heckenast Gusztáv. MDCCCLXI. Balassi Kiadó - Magyar Fotográfiai Múzeum.

\section{THE «AMERICAN MEMORIES» BY PÁL ROSTI: «TRAS LAS HUELLAS DE HUMBOLDT»}

\section{Summary}

The article presents the vision of Pál Rosti (1830-1874), geographer, anthropologist and Hungarian photographer, about his trip to Cuba, Venezuela and Mexico during 1856-1859, his opinion on various political, economic and social aspects observed in these countries and then drafted in his work entitled Memorias de un viaje por América (Úti emlékezetek Amerikából), published in 1861. Pál Rosti had participated in the war of Hungarian independence 18481849. After the defeat of the Hungarians had to leave the country.

Keywords: memories, travel literature, Latin America. 